Dataset: Labeled Bovine Brain

Peptide 1: Q(+28)DCDQFEK(+42)

Mapped To: sp|P02769|ALBU_BOVIN, N->D amino acid substitution

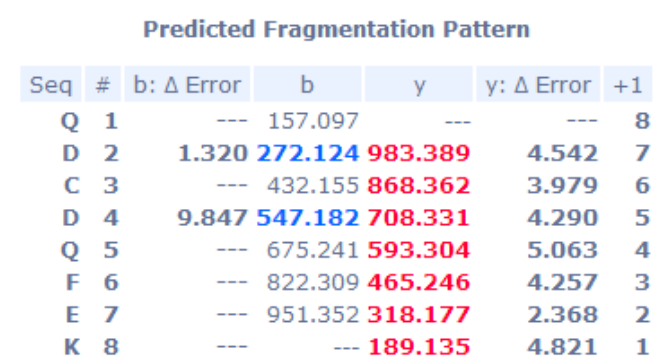

Predicted Fragmentation Pattern
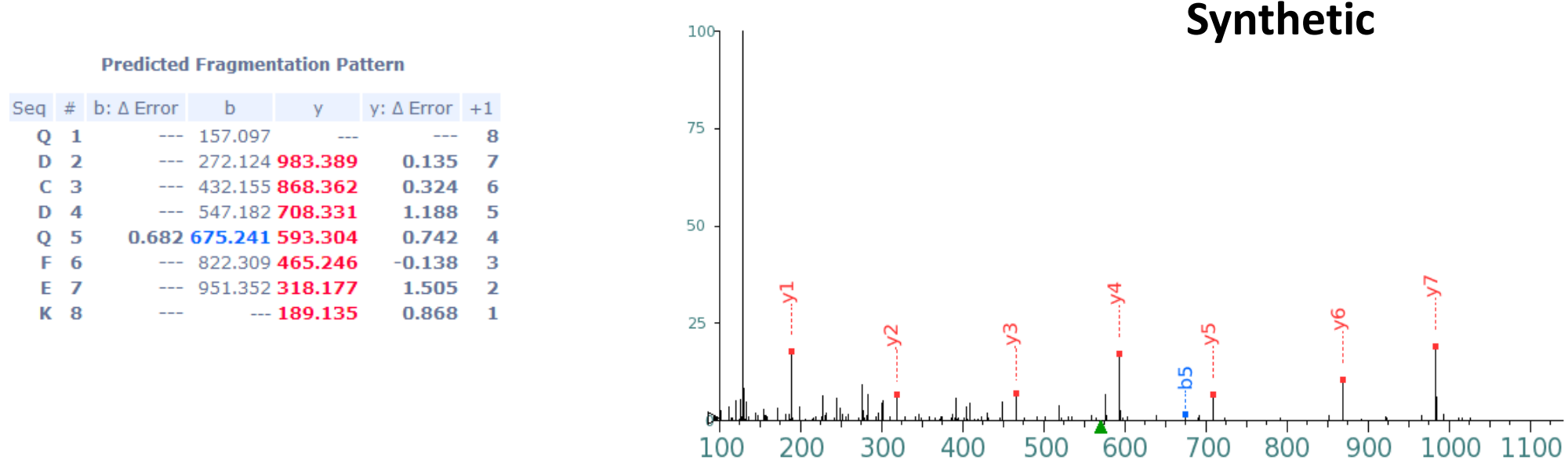
Dataset: Labeled Bovine Brain

Peptide 2: N(+28)SQGEEVAQRSTVFK(+42)

Mapped To: ref|NP_001096765.1| (bovine protein, not in database search space)
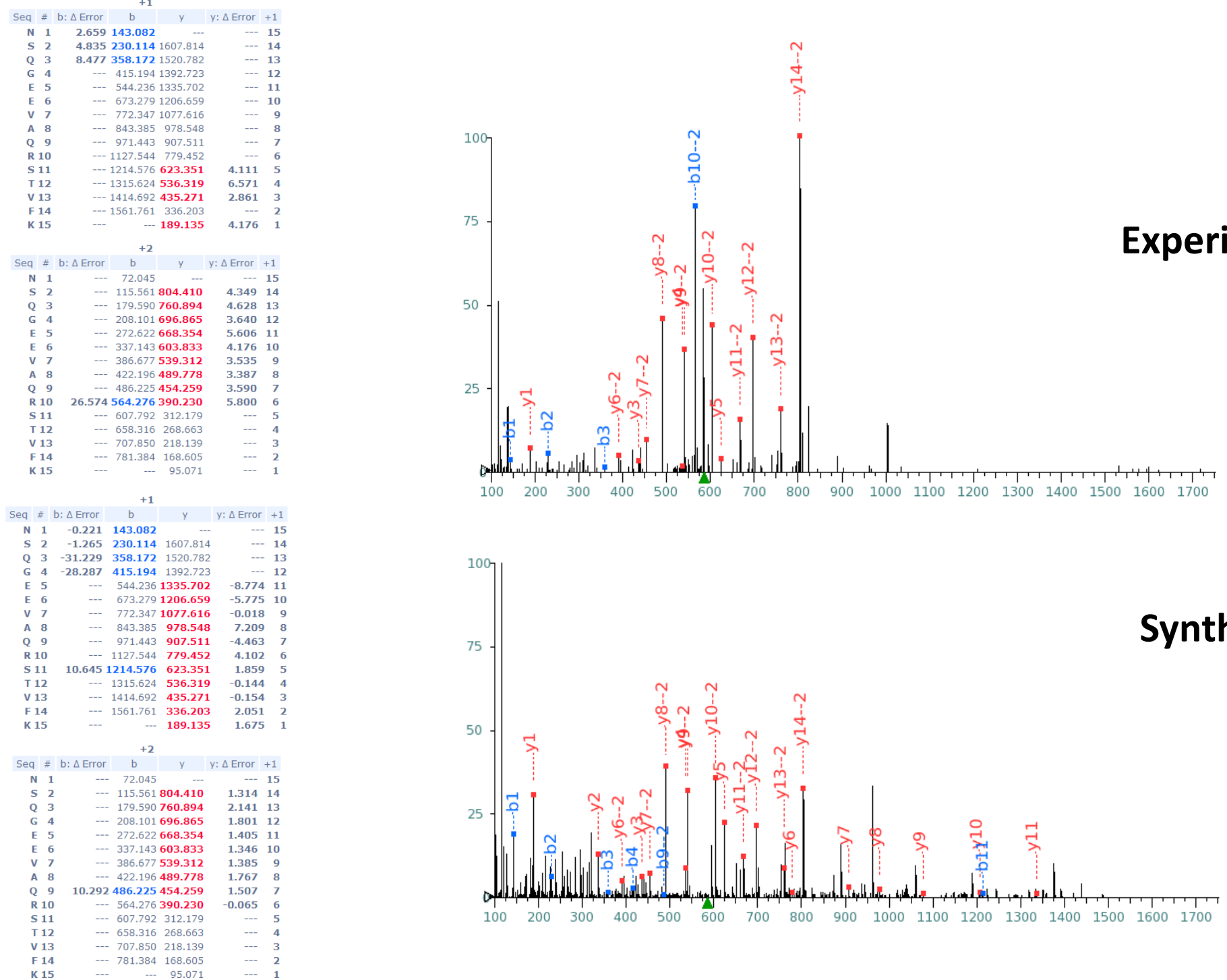
Dataset: Labeled Bovine Brain

Peptide 3: V(+28)VVCDDGTGFVK(+42)

Mapped To: sp|A7MB62|ARP2_BOVIN, N->D amino acid Substitution

Experiment

Predicted Fragmentation Pattern

\begin{tabular}{|c|c|c|c|c|c|c|}
\hline Seq & $\#$ & b: $\Delta$ Error & b & $y$ & $\mathrm{y}: \Delta$ Error & +1 \\
\hline v & 1 & --- & 128.107 & --- & --- & 12 \\
\hline v & 2 & 4.707 & 227.176 & 1238.583 & 2.542 & 11 \\
\hline v & 3 & 0.725 & 326.244 & 1139.515 & 1.311 & 10 \\
\hline C & 4 & --- & 486.275 & 1040.447 & -0.271 & 9 \\
\hline D & 5 & --- & 601.302 & 880.416 & 4.821 & 8 \\
\hline D & 6 & --- & 716.329 & 765.389 & 3.906 & 7 \\
\hline G & 7 & --- & 773.350 & 650.362 & 4.356 & 6 \\
\hline $\mathbf{T}$ & 8 & --- & 874.398 & 593.341 & --- & 5 \\
\hline G & 9 & --- & 931.419 & 492.293 & 10.754 & 4 \\
\hline & 10 & -2.153 & 1078.488 & 435.271 & --- & 3 \\
\hline & 11 & -- & 1177.556 & 288.203 & 15.628 & 2 \\
\hline & 12 & --- & ... & 189.135 & 3.853 & 1 \\
\hline
\end{tabular}

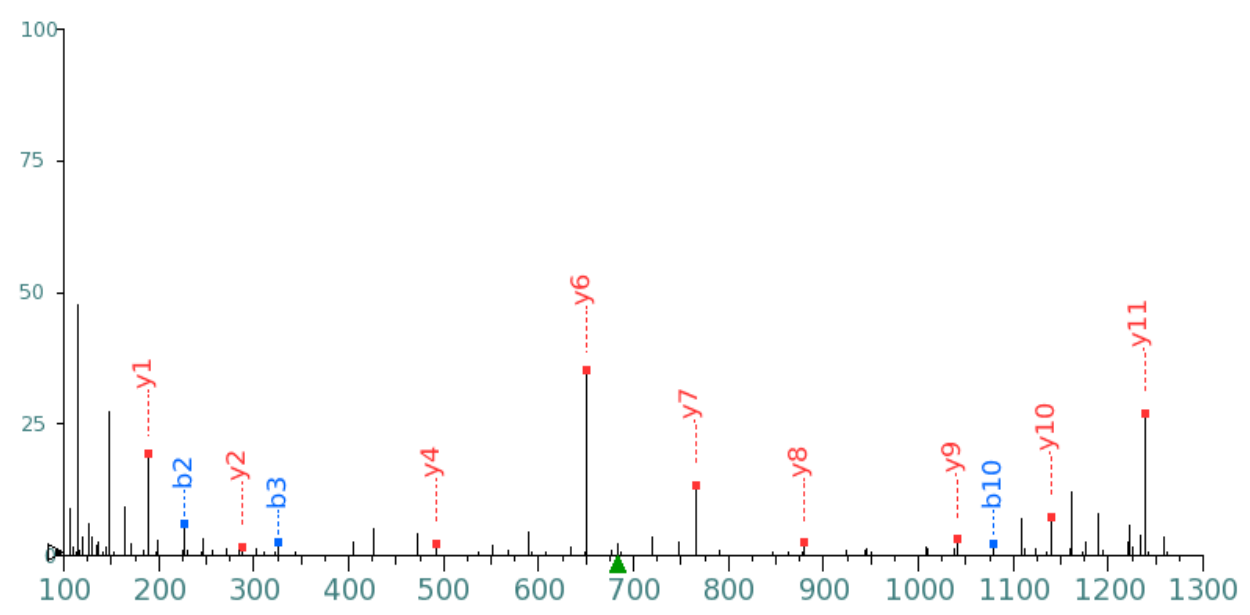

Synthetic

Predicted Fragmentation Pattern

\begin{tabular}{|c|c|c|c|c|c|c|}
\hline Seq & $\#$ & b: $\Delta$ Error & b & $y$ & $\mathrm{y}: \Delta$ Error & +1 \\
\hline v & 1 & --- & 128.107 & -- & --- & 12 \\
\hline v & 2 & -0.129 & 227.176 & 1238.583 & 0.422 & 11 \\
\hline v & 3 & -6.946 & 326.244 & 1139.515 & 1.257 & 10 \\
\hline C & 4 & -- & 486.275 & 1040.447 & 3.189 & 9 \\
\hline D & 5 & --- & 601.302 & 880.416 & -2.875 & 8 \\
\hline D & 6 & --- & 716.329 & 765.389 & 0.475 & 7 \\
\hline G & 7 & --- & 773.350 & 650.362 & 1.257 & 6 \\
\hline $\mathbf{T}$ & 8 & --- & 874.398 & 593.341 & 2.783 & 5 \\
\hline G & 9 & --- & 931.419 & 492.293 & 2.073 & 4 \\
\hline & 10 & -- & 1078.488 & 435.271 & -2.400 & 3 \\
\hline & 11 & --- & 1177.556 & 288.203 & -1.423 & 2 \\
\hline & 12 & --- & -- & 189.135 & 2.234 & 1 \\
\hline
\end{tabular}

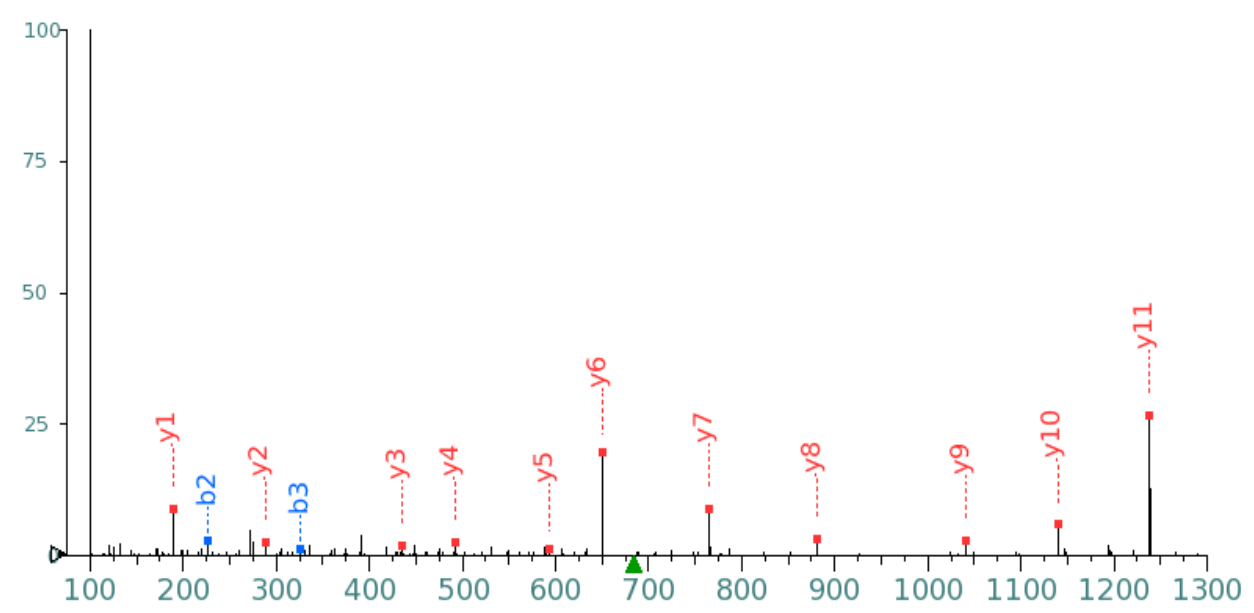




\section{Dataset: Yeast}

\section{Peptide 4: YGFAGFPVTDDGK}

\section{Mapped to: sp|P39567.1|IMDH1_YEAST, A->D amino acid substitution}

\section{Experiment}

Predicted Fragmentation Pattern

\begin{tabular}{|c|c|c|c|c|c|c|}
\hline Seq & \# & b: $\Delta$ Error & b & $y$ & y: $\Delta$ Error & +1 \\
\hline $\mathbf{Y}$ & 1 & --- & 164.071 & -- & --- & 13 \\
\hline G & 2 & 0.429 & 221.092 & 1210.574 & 0.381 & 12 \\
\hline $\mathbf{F}$ & 3 & 1.021 & 368.160 & 1153.552 & 0.699 & 11 \\
\hline A & 4 & 2.375 & 439.198 & 1006.484 & 0.371 & 10 \\
\hline G & 5 & 1.897 & 496.219 & 935.447 & 0.599 & 9 \\
\hline $\mathbf{F}$ & 6 & -13.091 & 643.287 & 878.425 & -9.530 & 8 \\
\hline $\mathbf{p}$ & 7 & --- & 740.340 & 731.357 & 0.729 & 7 \\
\hline v & 8 & --- & 839.409 & 634.304 & 1.369 & 6 \\
\hline T & 9 & --- & 940.456 & 535.236 & 1.838 & 5 \\
\hline D 1 & 10 & --- & 1055.483 & 434.188 & -1.437 & 4 \\
\hline D 1 & 11 & --- & 1170.510 & 319.161 & 3.388 & 3 \\
\hline G 1 & 12 & --- & 1227.532 & 204.134 & 1.390 & 2 \\
\hline K 1 & 13 & --- & -- & 147.113 & 0.855 & 1 \\
\hline
\end{tabular}

Predicted Fragmentation Pattern

\begin{tabular}{|c|c|c|c|c|c|c|}
\hline Seq & \# & b: $\Delta$ Error & b & $y$ & y: $\Delta$ Error & +1 \\
\hline $\mathbf{Y}$ & 1 & --- & 164.071 & --- & --- & 13 \\
\hline G & 2 & 2.154 & 221.092 & 1210.574 & 1.894 & 12 \\
\hline $\mathbf{F}$ & 3 & 2.347 & 368.160 & 1153.552 & 1.440 & 11 \\
\hline A & 4 & 2.444 & 439.198 & 1006.484 & 1.462 & 10 \\
\hline G & 5 & 1.836 & 496.219 & 935.447 & 1.643 & 9 \\
\hline $\mathbf{F}$ & 6 & 1.426 & 643.287 & 878.425 & 1.518 & 8 \\
\hline $\mathbf{p}$ & 7 & 8.289 & 740.340 & 731.357 & 1.647 & 7 \\
\hline v & 8 & -2.570 & 839.409 & 634.304 & 0.021 & 6 \\
\hline $\mathbf{T}$ & 9 & --- & 940.456 & 535.236 & 1.724 & 5 \\
\hline D 1 & 10 & --- & 1055.483 & 434.188 & 0.391 & 4 \\
\hline & 11 & --- & 1170.510 & 319.161 & 4.822 & 3 \\
\hline & 12 & --- & 1227.532 & 204.134 & 2.362 & 2 \\
\hline & 13 & --- & -- & 147.113 & -- & 1 \\
\hline
\end{tabular}

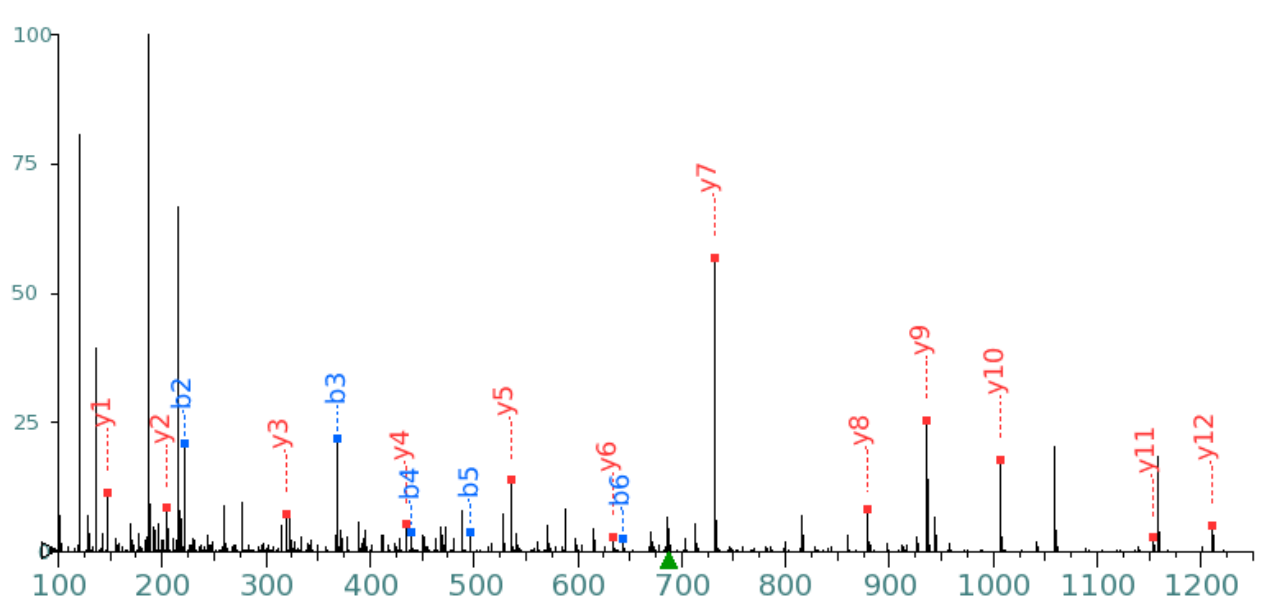

Synthetic

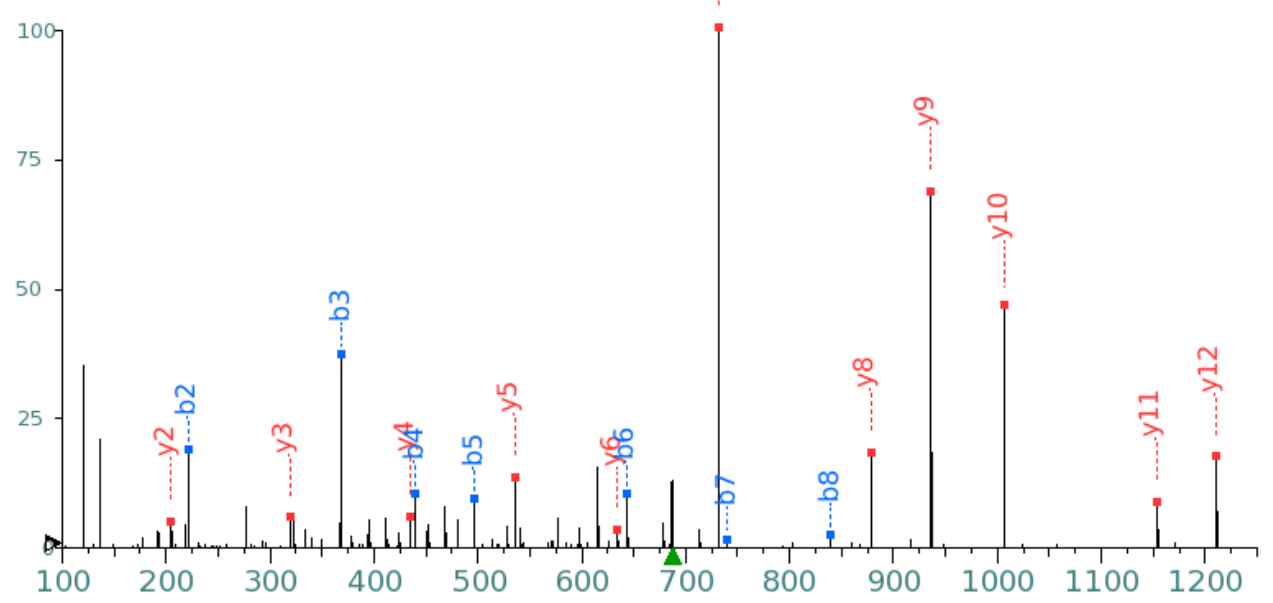




\section{Dataset: Yeast}

\section{Peptide 5: QQQQPVATPAK}

\section{Mapped to: gb|EGA63143.1|, yeast protein not in database search space}

Predicted Fragmentation Pattern

\begin{tabular}{|c|c|c|c|c|c|c|}
\hline Seq & $\#$ & b: $\Delta$ Error & b & $y$ & $\mathrm{y}: \Delta$ Error & +1 \\
\hline $\mathbf{Q}$ & 1 & 0.618 & 129.066 & -- & -- & 11 \\
\hline $\mathbf{Q}$ & 2 & -0.161 & 257.124 & 1067.584 & -6.321 & 10 \\
\hline $\mathbf{Q}$ & 3 & -0.699 & 385.183 & 939.526 & -0.508 & 9 \\
\hline Q & 4 & 2.599 & 513.242 & 811.467 & 0.745 & 8 \\
\hline $\mathbf{P}$ & 5 & -- & 610.294 & 683.409 & -0.032 & 7 \\
\hline v & 6 & -- & 709.363 & 586.356 & 0.950 & 6 \\
\hline A & 7 & --- & 780.400 & 487.287 & 0.691 & 5 \\
\hline T & 8 & 5.279 & 881.448 & 416.250 & 0.600 & 4 \\
\hline $\mathbf{P}$ & 9 & -- & 978.500 & 315.203 & -0.047 & 3 \\
\hline A & 10 & --- & 1049.537 & 218.150 & -0.493 & 2 \\
\hline & 11 & -- & -- & 147.113 & 0.025 & 1 \\
\hline
\end{tabular}

Predicted Fragmentation Pattern

\begin{tabular}{|c|c|c|c|c|c|c|}
\hline eq & $\#$ & b: $\Delta$ Error & b & $y$ & $\mathrm{y}: \Delta$ Error & +1 \\
\hline $\mathbf{Q}$ & 1 & --- & 129.066 & -- & - & 11 \\
\hline $\mathbf{Q}$ & 2 & 3.518 & 257. & 1067.584 & 11.059 & 10 \\
\hline $\mathbf{Q}$ & 3 & 2.153 & 385. & 939.526 & 3.649 & \\
\hline $\mathbf{Q}$ & 4 & 3.431 & 51 & 811 & 0.745 & \\
\hline $\mathbf{P}$ & 5 & --- & & 683 & & \\
\hline V & 6 & 10.108 & 709.363 & 586.356 & -1.652 & \\
\hline A & 7 & 17.629 & 780 & 487.287 & 2.320 & \\
\hline & 8 & 6.595 & 881.448 & 416.250 & 3.752 & \\
\hline 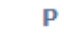 & 9 & --- & 978.500 & 315.203 & 2.760 & \\
\hline & 11 & 6.669 & 1049.537 & 218.150 & 6.362 & \\
\hline & & -- & $\cdots$ & 147.113 & 5.522 & \\
\hline
\end{tabular}

\section{Experiment}

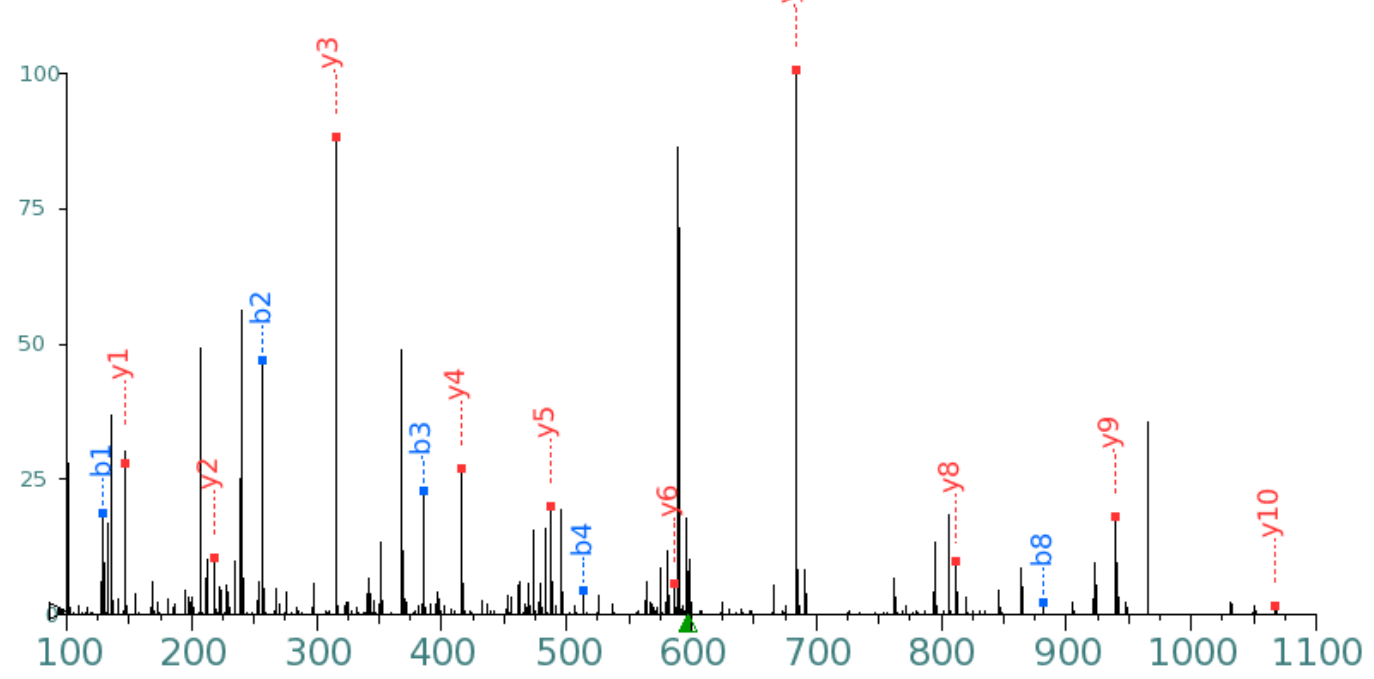

Synthetic

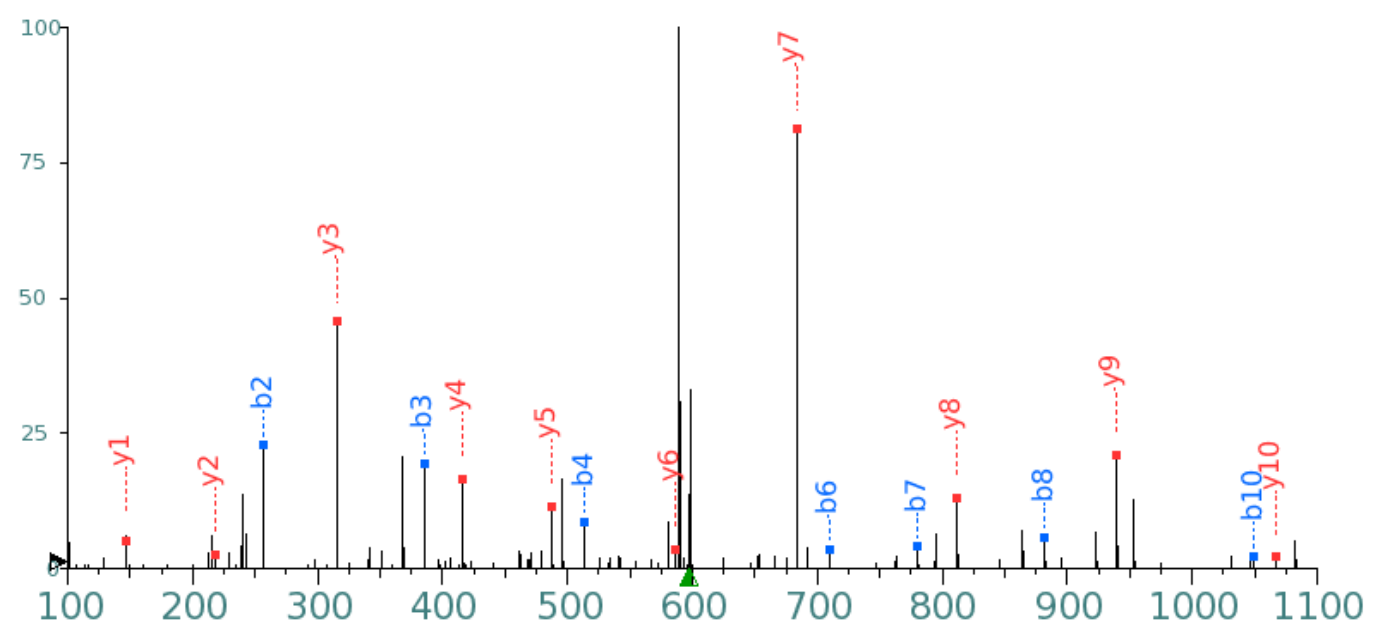




\section{Dataset: Yeast}

\section{Peptide 6: VVEEGEVPK}

Mapped to: Unable to map confidently to known sequence

\section{Experiment (Heavy SILAC Version)}

Predicted Fragmentation Pattern

\begin{tabular}{|c|c|c|c|c|c|c|}
\hline Seq & $\#$ & b: $\Delta$ Error & b & $y$ & $\mathrm{y}: \Delta$ Error & +1 \\
\hline v & 1 & --- & 100.076 & -- & --- & 9 \\
\hline v & 2 & -0.152 & 199.144 & 894.466 & -0.204 & 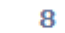 \\
\hline E & 3 & -6.852 & 328.187 & 795.397 & -0.084 & 7 \\
\hline $\mathbf{E}$ & 4 & --- & 457.229 & 666.355 & -0.755 & 6 \\
\hline G & 5 & --- & 514.251 & 537.312 & -1.181 & 5 \\
\hline $\mathbf{E}$ & 6 & --- & 643.293 & 480.291 & 2.257 & \\
\hline v & 7 & --- & 742.362 & 351.248 & 3.842 & 3 \\
\hline $\mathbf{P}$ & 8 & --- & 839.415 & 252.180 & -1.089 & 2 \\
\hline $\mathbf{K}$ & 9 & --- & -- & 155.127 & 0.977 & \\
\hline
\end{tabular}

Predicted Fragmentation Pattern

\begin{tabular}{|c|c|c|c|c|c|c|}
\hline Seq & \# & b: $\Delta$ Error & b & $y$ & $\mathrm{y}: \Delta$ Error & +1 \\
\hline v & 1 & --- & 100.076 & -- & --- & 9 \\
\hline v & 2 & 2.683 & 199.144 & 886.452 & 2.296 & 0 \\
\hline E & 3 & 3.563 & 328.187 & 787.383 & 2.421 & \\
\hline E & 4 & 0.843 & 457.229 & 658.341 & 2.047 & \\
\hline G & 5 & 0.433 & 514.251 & 529.298 & 3.105 & \\
\hline E & 6 & 1.500 & 643.293 & 472.277 & 0.270 & \\
\hline v & 7 & -1.734 & 742.362 & 343.234 & 2.211 & \\
\hline $\mathbf{P}$ & 8 & --- & 839.415 & 244.166 & 2.707 & \\
\hline 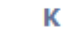 & 9 & --- & -- & 147.113 & 7.493 & \\
\hline
\end{tabular}
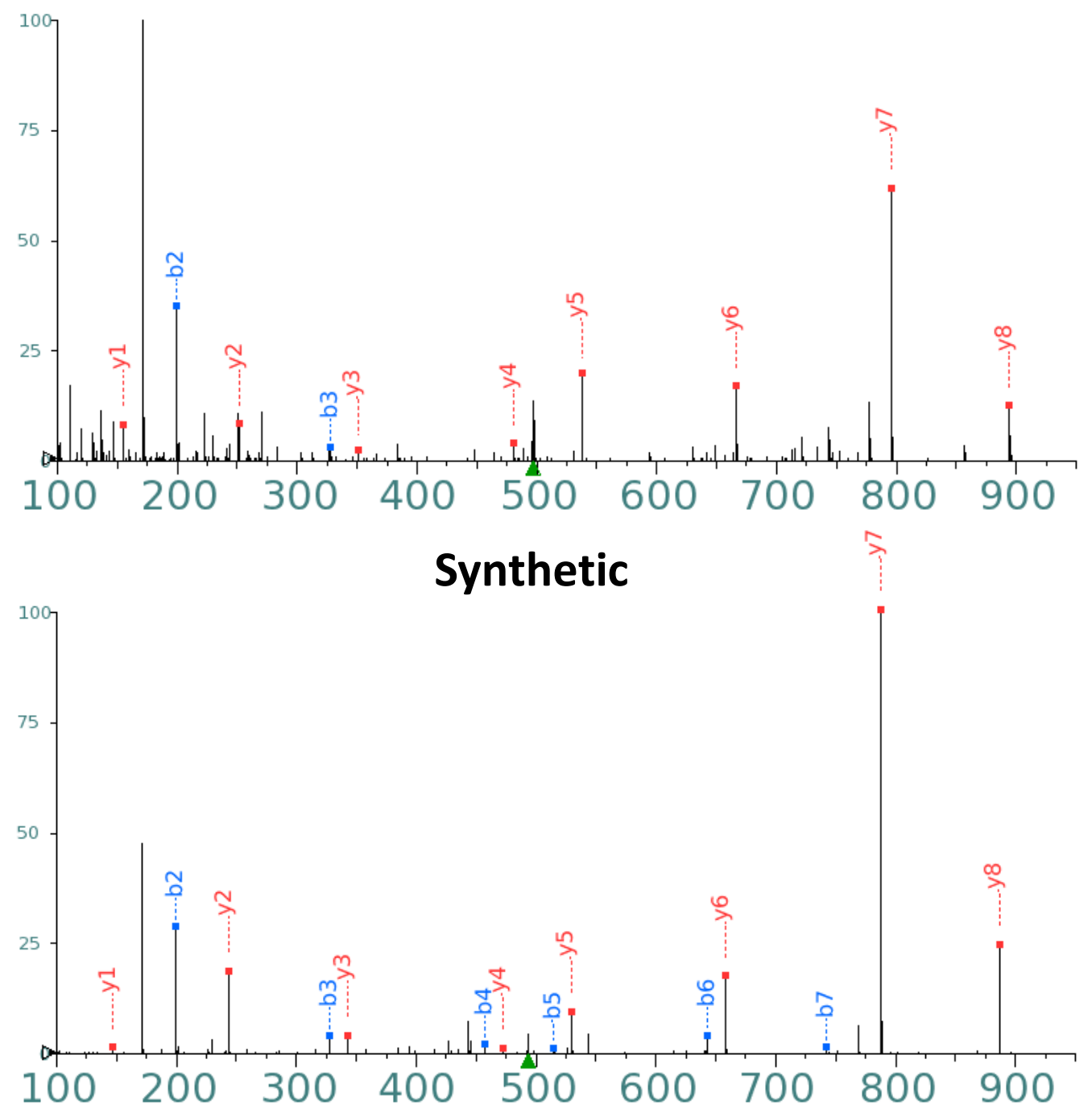


\section{Dataset: Yeast}

\section{Peptide 7: AVFNDARK}

Mapped to: ref|NP_042580.1|, S. cer. virus L-A

\section{Experiment}

Predicted Fragmentation Pattern

\begin{tabular}{|c|c|c|c|c|c|c|}
\hline eq & $\#$ & b: $\Delta$ Error & b & $y$ & $\mathrm{y}: \Delta$ Error & +1 \\
\hline A & 1 & --- & 72.044 & -- & --- & \\
\hline v & 2 & -0.509 & 171.113 & 849.458 & -1.251 & \\
\hline $\mathbf{F}$ & 3 & 1.713 & 318.181 & 750.389 & -0.530 & \\
\hline $\mathbf{N}$ & 4 & --- & 432.224 & 603.321 & -0.063 & \\
\hline D & 5 & --- & 547.251 & 489.278 & 0.711 & \\
\hline A & 6 & --- & 618.288 & 374.251 & -0.549 & \\
\hline $\mathbf{R}$ & 7 & --- & 774.389 & 303.214 & 4.470 & \\
\hline $\mathbf{K}$ & 8 & --- & & 147.113 & -0.286 & \\
\hline
\end{tabular}

Predicted Fragmentation Pattern

\begin{tabular}{|c|c|c|c|c|c|c|}
\hline eq & $\#$ & b: $\Delta$ Error & b & $y$ & $\mathrm{y}: \Delta$ Error & +1 \\
\hline $\mathbf{A}$ & 1 & -- & 72.044 & -- & --- & 8 \\
\hline v & 2 & 3.326 & 171.113 & 849.458 & 1.048 & 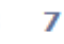 \\
\hline $\mathbf{F}$ & 3 & 2.001 & 318.181 & 750.389 & 2.886 & \\
\hline $\mathbf{N}$ & 4 & --- & 432.224 & 603.321 & 2.770 & \\
\hline D & 5 & --- & 547.251 & 489.278 & 3.019 & \\
\hline A & 6 & -- & 618.288 & 374.251 & 1.571 & \\
\hline $\mathbf{R}$ & 7 & 7.369 & 774.389 & 303.214 & -- & \\
\hline K & 8 & -- & -- & 147.113 & 6.352 & \\
\hline
\end{tabular}
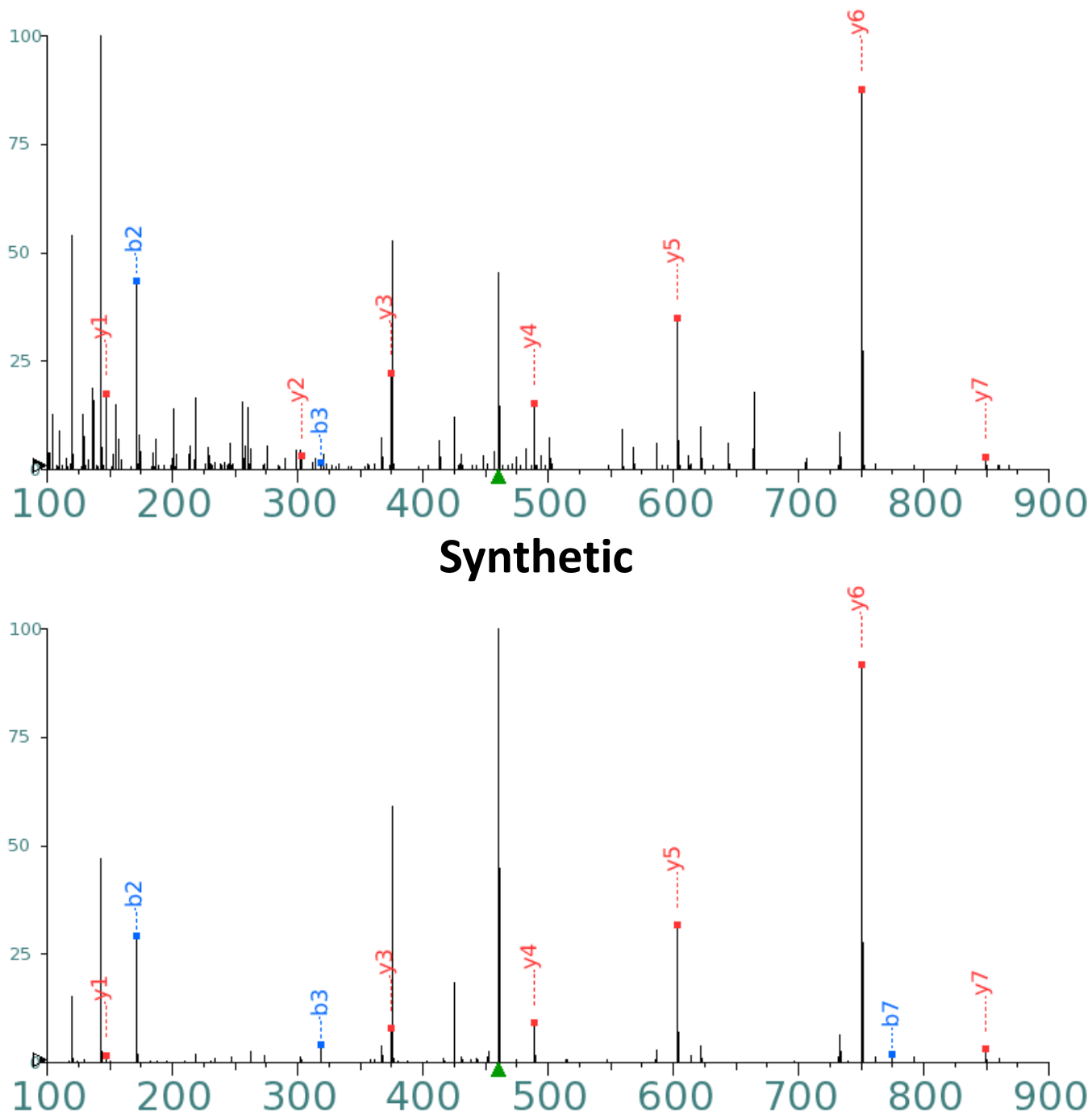